\title{
ACCESSORY SPLEEN HYPERTROPHY MIMICKING COLON CANCER METASTASIS
}

\author{
I. Ates*, O. Yazici, D. Yazilitas, N. Ozdemir, N. Zengin \\ Department of Oncology, Ankara Numune Education and Research Hospital, Ankara 06100, Turkey
}

Accessory spleen is a congenital form of an ectopic splenic tissue. In this report, we present a case of a patient who was followed with the diagnosis of rectal and sigmoid colon cancer and an accessory spleen hypertrophy, which was thought to be colon cancer metastasis in the left hypochondriac region. After colectomy and splenectomy, accessory spleen that mimics cancer metastasis was diffrentially diagnosed using scintigraphy.

Key Words: accessory spleen, colon cancer, splenectomy.

The accessory spleen is a congenital form of an ectopic splenic tissue. It is frequently seen in members of the public. Also, the prevalence was found to be between 10 and $30 \%$ at autopsy series [1]. They are typically smaller than $2 \mathrm{~cm}$ in diameter, well demarcated, round, solitary nodules that appear homogeneous at contrast imaging [2]. Although accessory spleen is usually asymptomatic and is often discovered incidentally, it is important in some diseases. In this report an accessory spleen hypertrophy, which was thought to be colon cancer metastasis, is going to be discussed and a differential diagnosis was made with scintigraphy.

Sigmoid colon resection after neoadjuvant chemoradiotherapy has been performed on a 67-year-old male patient who was treated because of the rectum and sigmoid colon cancer. During resection splenectomy was done because of the adhesion of splenic flexure to the spleen. In the investigation tests after the operation, it was reported that there was no lesion in spleen logy and there was a $2 \mathrm{~cm}$ hypodense lesion in the liver. After 4 cycles FOLFOX therapy was given, and the patient followed without treatment. When the patient came to the control examination one and a half years after the operation, abdominal computed tomography was studied and $22 \times 20 \mathrm{~mm}$ sized, well-circumscribed nodular soft tissue density was observed in the neighbourhood of the colon wall at the level of splenic flexure in the joining point of descending and transverse colon. Although accessory spleen hypertrophy was thought of at the forefront, colon carcinoma metastasis was also considered in the differential diagnosis. Spleen scintigraphy was done to create a differential diagnosis (Figure). The result was consistent with splenic hypertrophy. After splenectomy, two types of residual splenic tissue can be seen with the names of accessory spleens and splenosis.

The accessory spleen is a congenital condition that occurs during embryonic development, usually under $4 \mathrm{~cm}$ but splenosis is the autotransplantation of developing splenic tissue after splenectomy or splenic trauma [3]. In a study done with computed tomography scans that involved 1000 people, the average of accessory spleen diameter was found to be $16.8 \mathrm{~mm}$, the smallest and the

Submitted: June 16, 2016.

${ }^{\star}$ Correspondence: E-mail: dr.ihsanates@hotmail.com largest diameter was found to be 8-32 mm [1]. In an accessory spleen scan that Beahrs et al. [4] have done with 8000 people who have normal sized spleen, accessory spleens greater than $2.5 \mathrm{~cm}$ were not found in any patient. In our case, accessory spleen size was about $2 \mathrm{~cm}$. In the literature, there are a lot of accessory spleen cases that mimic malignancy and at further investigation are understood to be an accessory spleens. They are frequently presented as adnexal mass [5], retroperitoneal tumors, pancreatic mass [6, 7], adrenal masses [8] and kidney cancer [9]. In this patient who was followed because of colon cancer and splenectomy, metastasis was considered in the first plan because of his history when a lesion was detected in the spleen logy at control tests. The accessory spleen was diagnosed with the splenic scintigraphy.
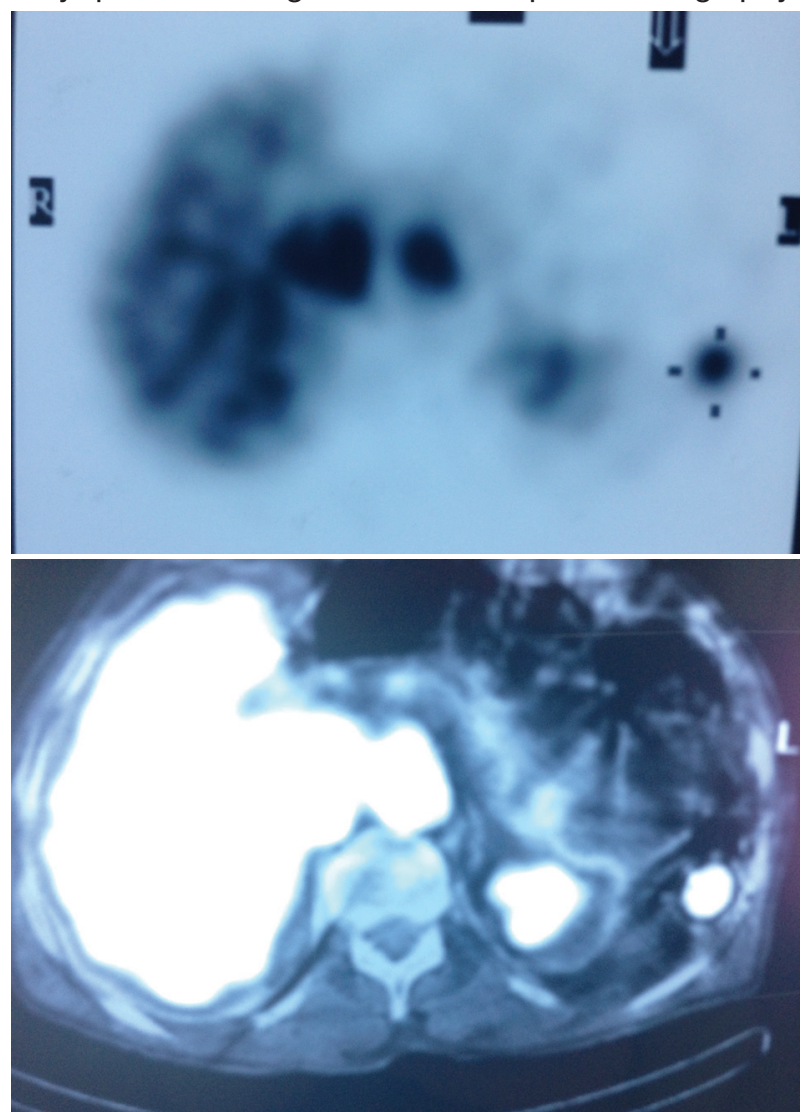

Figure. Spleen scintigraphy, showing accessory spleen

Accessory spleen must be considered in detected intra-abdominal masses. Differential diagnosis with 
gold standard spleen scintigraphy should be performed without resorting to invasive tests such as surgery.

\section{CONFLICT OF INTEREST}

The authors declare no conflict of interest.

\section{REFERENCES}

1. Halpert B, Gyorkey F. Lesions observed in accessory spleens of 311 patients. Am J Clin Pathol 1959; 32: 165-8.

2. Mortele KJ, Mortele B, Silverman SG. CT features of the accessory spleen. Am J Roentgenol 2004; 183: 1653-7.

3. Fremont RD, Rice TW. Splenosis: a review. South Med J 2007; 100: 589-93.

4. Beahrs JR, Stephens DH. Enlarged accessory spleens: CT appearance in postsplenectomy patients. Am J Roentgenol 1980; 135: 483-6.
5. Hsiao SM, Lee LC, Chang MH. Large pelvic accessory spleen mimicking an adnexal malignancy in a teenage girl. J Formos Med Assoc 2001; 100: 565-7.

6. Harris AC, Chaudry MA, Menzies D, et al. Laparoscopic resection of an epidermoid cyst within an intrapancreatic accessory spleen: a case report and review article. Surg Laparosc Endosc Percutan Tech 2012; 22: e246-9.

7. Harris GN, Kase DJ, Bradnock H, et al. Accessory spleen causing a mass in the tail of the pancreas: MR imaging findings. Am J Roentgenol 1994; 163: 1120-1.

8. Stiris MG. Accessory spleen versus left adrenal tumor: computed tomographic and abdominal angiographic evaluation. J Comput Assist Tomogr 1980; 4: 543-4.

9. Tjaden C, Werner J, Buechler MW, et al. Reactive hypertrophy of an accessory spleen mimicking tumour recurrence of metastatic renal cell carcinoma. Asian J Surg 2011; 34: 50-2. 